\title{
Support effect on electrocatalytic performance of methanol oxidation over platinum catalysts
}

\author{
$\mathrm{Ke} \mathrm{Gu}^{1}$, JingWei $\mathrm{Li}^{1}{ }^{1, \mathrm{a}}$, Jianguo Zhao, Yajuan Liu ${ }^{1, \mathrm{a}}$, Jun Qiao ${ }^{1}$, Dongdong Chen ${ }^{2}$, Siyu Hou ${ }^{1}$, Ran Zhang ${ }^{1}$ \\ ${ }^{1}$ Institute of Carbon Materials Science, Shanxi Datong University, Datong, 037009, China \\ ${ }^{2}$ Department of Chemistry \& Chemical Engineering, Lvliang University, Lvliang, 033001, China
}

\begin{abstract}
Graphene oxide and carbon nanotubes supported Pt nanoparticles were successfully synthesized by wet chemical reduction method. The structures and methanol oxidation performance of the two catalysts were characterized by scanning electron microscope (SEM), transmission electron microscope (TEM), X-ray diffraction (XRD), Raman spectroscopy (Raman) and electrochemical workstation. The results show that graphene oxide supported Pt nanoparticles exhibits higher electrochemical active surface area, methanol oxidation activity and stability compared with carbon nanotubes. It is proposed that the well dispersed Pt on the graphene oxide plays an important role for the excellent performancefor methanol oxidation.
\end{abstract}

\section{Introduction}

Fuel cell is a kind of environment-friendly energy ${ }^{[1,2]}$, which is powered by renewable small molecular substances, such as hydrogen ${ }^{[3,4]}$, ethanol ${ }^{[2,5]}$, formic $\operatorname{acid}^{[6,7]}$, methanol. Methanol oxidation on the anodic surface of direct methanol fuel cell (DMFC) is a slow kinetic process, which involves multi-electron and multi-step elementary reactions ${ }^{[8-10]}$. It constitutes the rate control step of the total reaction of the fuel cell and determines the efficiency of the direct methanol fuel cell to a great extent. Nowadays, Pt supported catalyst is widely used as the commercialized catalysts in the fuel cell. At the same time, Pt catalysts are vulnerable to chemical and electrochemical corrosion. Therefore, a large number of precious metal platinum is needed to catalyze the occurrence of methanol oxidation reaction efficiently ${ }^{[11-13]}$. Based on the fact that $\mathrm{Pt}$ is fairly expensive and difficult to replace by other components, one of the biggest issues is how to improve the utilization and stability of Pt effectively. Carbon is the most widely used support in both anode and cathode of DMFC owing to its large specific surface area, good electrochemical stability and remarkable electrical conductivity. As a consequence, $\mathrm{Pt} / \mathrm{C}$ catalysts have aroused growing interest. For $\mathrm{Pt} / \mathrm{C}$ catalysts, the structure or properties of the catalyst carrier directly determine the dispersion, coordination, crystal structure, electronic properties and interaction of the active components, thus affecting the activity of the catalytic reaction. In this experiment, graphene oxide $(\mathrm{GO})$ and carbon nanotubes (CNTs) were used as carriers to systematically study the catalytic performance of Pt catalysts supported on different kind of carbon supports for methanol oxidation.

In this paper, the preparation methods and catalytic performance for two kinds of $\mathrm{Pt}$ supported catalysts were compared. The platinum catalysts supported on graphene oxide were prepared by 1-ethyl-3-methylimidazolium tetrafluoroborate ([BMIM] $\left.\left[\mathrm{BF}_{4}\right]\right)$ assisted ethylene glycol reduction method ${ }^{[14,15]}$, denoted as $\mathrm{Pt} / \mathrm{GO}$; Pt supported on carbon nanotubes were prepared by wet chemical reduction method, denoted as Pt/CNTs. The physical property of the catalysts were characterized by TEM, SEM, Raman and XRD. The catalytic performance of the two catalysts for methanol oxidation were investigated by electrochemical methods.

\section{Experimental}

\subsection{Preparation of $\mathrm{Pt}$ nanoparticles supported on graphene oxide}

\subsubsection{Pretreatment of GO}

$50 \mathrm{mg}$ GO was added to a mixture solution of $25 \mu \mathrm{L}$ [BMIM] $\left[\mathrm{BF}_{4}\right], 50 \mathrm{~mL}$ deionized water and $100 \mathrm{~mL}$ ethylene glycol with vigorous stirring for $3 \mathrm{~h}$. Then the GO suspension was transferred into a cell crusher. The setting parameters of the crusher are as follows: $60 \%$ power and stop for $2.5 \mathrm{~s}$ after ultrasonic $1 \mathrm{~s}$ for $2 \mathrm{~h}$. After

\footnotetext{
a Corresponding author: bjyddx1988@163.com; dtdxliuyajuan@139.com
} 
crushing, GO was washed and isolated by centrifugation with a speed of $10000 \mathrm{rpm}$. The obtained sample was dried at $100{ }^{\circ} \mathrm{C}$ for $6 \mathrm{~h}$ and ground for use.

\subsubsection{Preparation of Pt/GO}

$20 \mathrm{mg}$ GO was added to a mixture solution of $20 \mathrm{~mL}$ deionized water and $40 \mathrm{~mL}$ ethylene glycol in a $100 \mathrm{~mL}$ round bottom flask. Then, the above GO suspension was placed in oil bath with vigorous stirring. When the temperature of the reaction solution rose to $125^{\circ} \mathrm{C}, 3.62$ $\mathrm{mL} \mathrm{H}_{2} \mathrm{PtCl}_{6} \cdot 6 \mathrm{H}_{2} \mathrm{O}$ aqueous solution with a concentration of $15 \mathrm{mmol} / \mathrm{L}$ was dripped into it in three times and kept at $125{ }^{\circ} \mathrm{C}$ for $4 \mathrm{~h}$. After cooling down to room temperature, the sample was washed three times with deionized water and dried overnight in vacuum at $60{ }^{\circ} \mathrm{C}$.

\subsection{Preparation of $\mathrm{Pt}$ nanoparticles supported on carbon nanotubes}

\subsubsection{Pretreatment of CNTs}

The CNTs was pretreated by oxidation with the reflux of concentrated nitric acid. The slurry of CNTs and concentrated nitric acid $(68 \mathrm{wt} \%)$ with the mass ratio of 1 : 100 was put in oil bath and reflux at $100{ }^{\circ} \mathrm{C}$ for $5 \mathrm{~h}$. Then, the mixture was filtered, washed and dried at $80{ }^{\circ} \mathrm{C}$ for 6 h.

\subsubsection{Preparation of Pt/CNTs}

The $\mathrm{Pt} / \mathrm{CNTs}$ catalyst was prepared by wet chemical reduction method. Typically, $0.1650 \mathrm{~g}$ CNTs was added to $10 \mathrm{~mL}$ ethylene glycol (EG). Then $10 \mathrm{~mL} \mathrm{H}_{2} \mathrm{PtCl}_{6}$-EG solution of $(8 \mathrm{~mol} / \mathrm{L})$ is added to the above suspension and the $\mathrm{pH}$ value was adjusted to 11 with $\mathrm{NaOH}$. The resultant reaction mixture was transferred into a $100 \mathrm{~mL}$ Teflon-lined autoclave, which was then sealed and kept in the electric oven at $130{ }^{\circ} \mathrm{C}$ for $3 \mathrm{~h}$. After cooling to room temperature, the precipitates were collected by centrifugation, repeatedly washed by deioned water, and dried in air at $100^{\circ} \mathrm{C}$ for $12 \mathrm{~h}$.

\subsection{Materials Characterizations}

The morphologies and microstructures were obtained by TEM (JEM2100) and SEM (TESCAN, MAIA3LMH). The XRD data were recorded on X-ray diffractometer (Rigaku, SmartLabSE). The crystal structure and degree of graphite were analyzed by Raman (Invia, RenishawInstruments, England).

\subsection{Electrochemical measurements}

The electrochemical test was carried out on the Shanghai Chenghua chi $760 \mathrm{E}$ electrochemical workstation. The whole test process was carried out using a three-electrode battery with glass carbon working electrode, and the counter electrode was composed of platinum wire and $\mathrm{Ag} / \mathrm{AgCl}$ reference electrode. $2 \mathrm{mg}$ catalyst was added to the solution of $450 \mathrm{~mL}$ ethanol solution, $450 \mathrm{~mL}$ distilled water and $50 \mathrm{~mL}$ Nafion $(5 \mathrm{wt} \%)$ solution with stirring for $0.5 \mathrm{~h}$, and then $5 \mathrm{uL}$ above slurry was transferred to the surface of glassy carbon electrode to prepare working electrode. Before the measurement, high purity $\mathrm{N}_{2}$ was injected into the electrolyte solution for $10 \mathrm{~min}$ to remove dissolved oxygen.

The cyclic voltammetric (CV) experiment was carried out in the electrolyte solution of $0.5 \mathrm{M} \mathrm{H}_{2} \mathrm{SO}_{4}$ with the scanning speed of $50 \mathrm{mV} / \mathrm{s}$. Methanol oxidation activity was determined in $0.5 \mathrm{M} \mathrm{H}_{2} \mathrm{SO}_{4}$ and $1 \mathrm{M} \mathrm{CH}_{3} \mathrm{OH}$ solutions. The chronoelectric current was measured in 0.5 $\mathrm{M} \mathrm{H}_{2} \mathrm{SO}_{4}$ and $1 \mathrm{M} \mathrm{CH}_{3} \mathrm{OH}$ solutions. All the experiments were carried out in high purity $\mathrm{N}_{2}$ at room temperature.

\section{Results and discussion}

The morphologies and microstructures of $\mathrm{Pt} / \mathrm{GO}$ and Pt/CNTs catalysts were observed by SEM and TEM as shown in Fig. 1 and 2. From Fig. 1, it can be seen the GO observed is of few-layer with varying lengths between 2 $\mu \mathrm{m}$ and $6 \mu \mathrm{m}$ based on SEM analysis. In the case of CNTs, they exhibit average width of ca. $20 \mathrm{~nm}$ and length of $10 \mu \mathrm{m} \sim 100 \mu \mathrm{m}$. As indicated in Fig. 2, it can be clearly found that Pt nanoparticle were uniformly loaded on GO and CNTs carriers with the average size of $1.2 \mathrm{~nm}$ and $2.6 \mathrm{~nm}$. The smaller particle size of $\mathrm{Pt}$ is more favorable on account of fully exposing the active sites in the catalytic process, thus improving the utilization of $\mathrm{Pt}$.

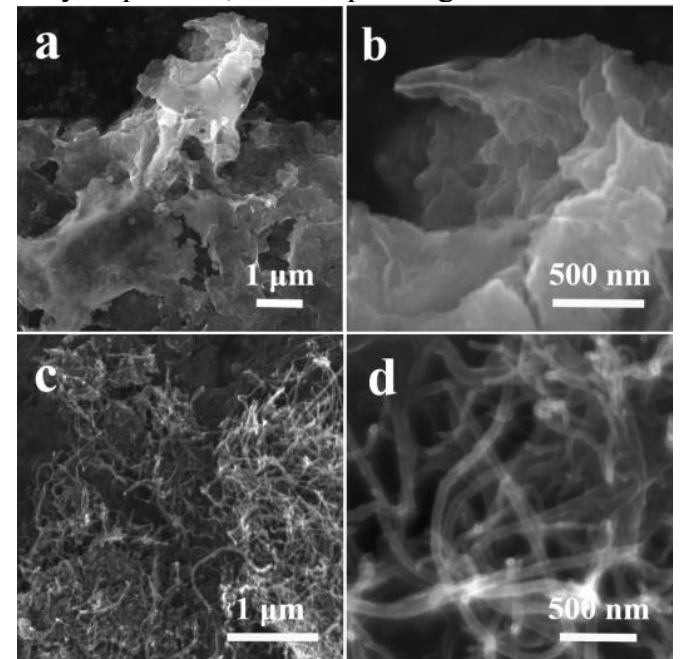

Figure 1. SEM images of $\mathrm{Pt} / \mathrm{GO}(\mathrm{a}, \mathrm{b})$ and $\mathrm{Pt} / \mathrm{CNTs}(\mathrm{c}, \mathrm{d})$ catalysts 


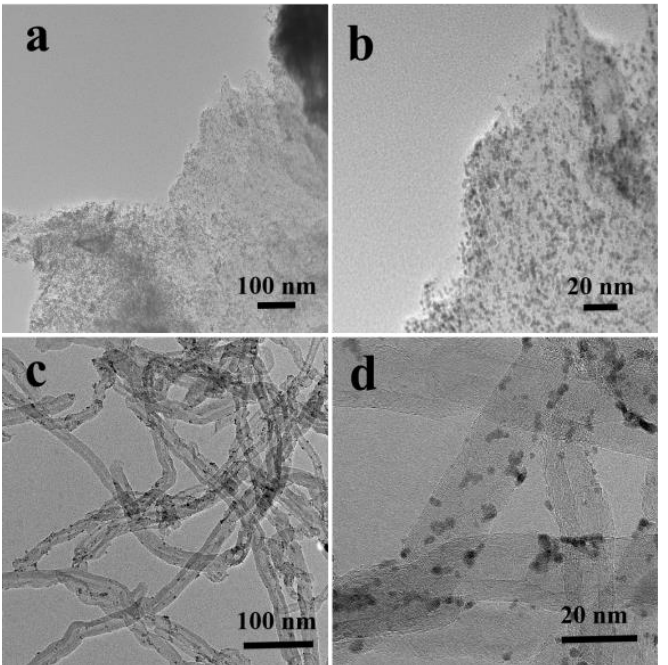

Figure 2. TEM or HRTEM images of $\mathrm{Pt} / \mathrm{GO}(\mathrm{a}, \mathrm{b})$ and $\mathrm{Pt} / \mathrm{CNTs}$ (c, d) catalysts

Raman spectra are usually used to indicate the degree of graphitization of materials. Fig. 3 shows the Raman curves of the two catalysts. It can be seen that both catalysts have a D peak at $1300 \mathrm{~cm}^{-1}$ and a $G$ peak at $1600 \mathrm{~cm}^{-1}$. The $\mathrm{D}$ peak corresponds to the disorder degree caused by the defects in the material itself, while the $G$ peak corresponds to the intrinsic peak of the graphite structure, which represents the stretching vibration of the $\mathrm{sp}^{2}$ hybrid of the carbon atom. The disorder degree of graphite materials is usually characterized by the intensity ratio of $D$ peak to $G$ peak $\left(\mathrm{I}_{\mathrm{D}} / \mathrm{I}_{\mathrm{G}}\right)^{[16]}$. The value of $\mathrm{Pt} / \mathrm{GO}$ is 1.03 , which is similar to that of Pt/CNTs (1.06), indicating that the two catalysts exhibit approximate degree of graphitization and electrical conductivity.

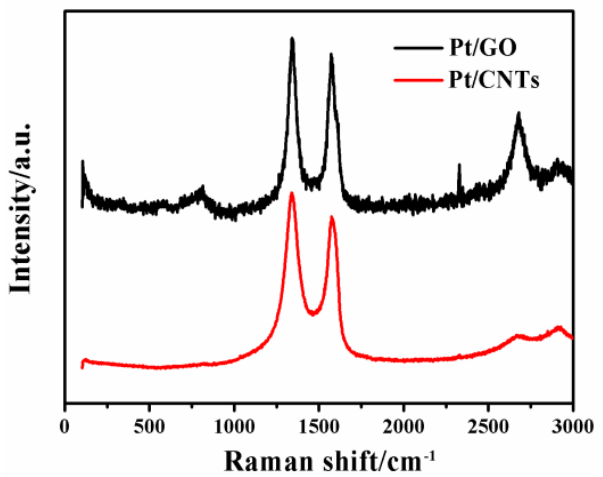

Figure 3. Raman spectroscopy characterization of $\mathrm{Pt} / \mathrm{GO}$ and $\mathrm{Pt} / \mathrm{CNTs}$ catalysts

Wide angle XRD patterns of $\mathrm{Pt} / \mathrm{CNTs}$ and $\mathrm{Pt} / \mathrm{GO}$ catalysts are showed in Fig. 4. The prominent peaks at $25^{\circ}, 39.8^{\circ}, 46.4^{\circ}$ and $67.6^{\circ}$ were observed. The peak near $25^{\circ}$ belongs to the carbon (002) crystal plane, which usually indicates that the carbon material has good electrical conductivity. The peaks of $39.8^{\circ}, 46.4^{\circ}$ and $67.6^{\circ}$ correspond to the crystal plane of Pt (111), (200) and (220) respectively ${ }^{[17]}$, indicating that the precious metal Pt is completely deposited on the surface of the carrier.

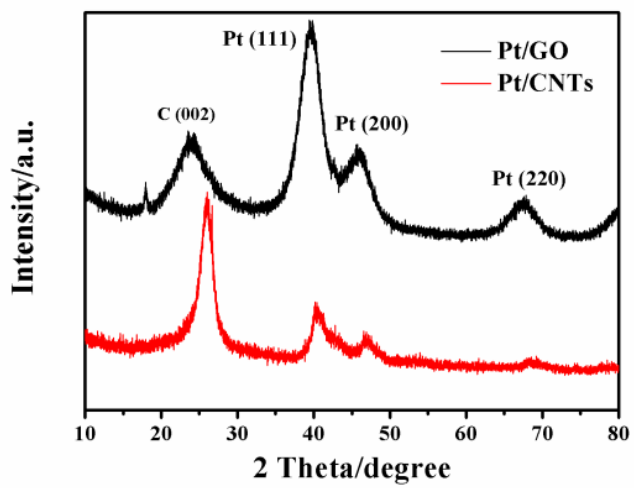

Figure 4. XRD patterns of $\mathrm{Pt} / \mathrm{GO}$ and $\mathrm{Pt} / \mathrm{CNTs}$

The electrochemical active surface area (ECSA) of the catalysts was estimated by cyclic voltammetry (CV). The test environment was $\mathrm{N}_{2}$ saturated $0.5 \mathrm{M} \mathrm{H}_{2} \mathrm{SO}_{4}$ solution with a scanning rate of $50 \mathrm{mV} / \mathrm{s}$. The results are as shown in the Fig. 5. The ECSA of Pt/GO is $66.6 \mathrm{~m}^{2} \mathrm{~g}^{-1}$. As contrast, that of $\mathrm{Pt} / \mathrm{CNTs}$ is only $3.7 \mathrm{~m}^{2} \mathrm{~g}^{-1}$. Such a ECSA of provided the $\mathrm{Pt} / \mathrm{GO}$ electrochemical accessibility.

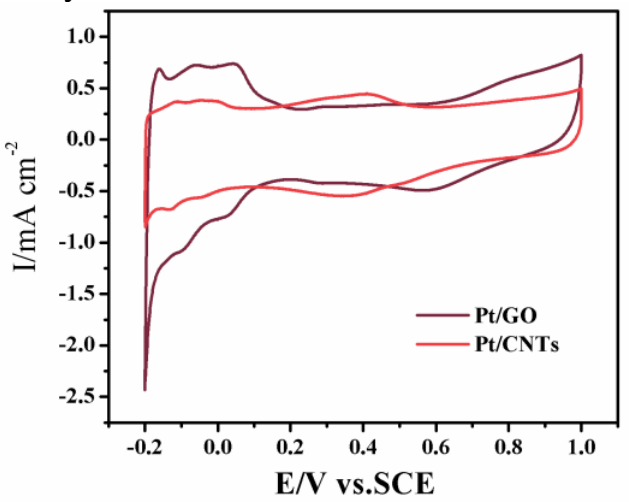

Figure 5. Cyclic voltammograms of the $\mathrm{Pt} / \mathrm{GO}$ and $\mathrm{Pt} / \mathrm{CNT}$

Fig. 6 exhibits the activities of the catalysts for methanol oxidation were tested in $0.5 \mathrm{M} \mathrm{H}_{2} \mathrm{SO}_{4}$ and $1 \mathrm{M}$ $\mathrm{CH}_{3} \mathrm{OH}$ solutions by means of $\mathrm{CV}$ test. The oxidation peak in the anodic scanning (forward scanning) process is caused by methanol oxidation, and that in the cathodic scanning (reverse scanning) process is caused by the further oxidation of the carbon-containing intermediates produced in the anodic scanning process ${ }^{[18]}$. It can be seen that the mass specific activities of $\mathrm{Pt} / \mathrm{GO}$ and $\mathrm{Pt} / \mathrm{CNTs}$ catalysts are $253.5 \mathrm{~mA} \cdot \mathrm{mg}^{-1}$ and $95.95 \mathrm{~mA} \cdot \mathrm{mg}^{-1}$, respectively. The electrocatalytic performance of $\mathrm{Pt} / \mathrm{GO}$ catalyst for methanol oxidation is better than that of $\mathrm{Pt} / \mathrm{CNTs}$ catalyst, which is mainly due to the better dispersion of $\mathrm{Pt}$ on $\mathrm{GO}$ carrier, smaller particle size of $\mathrm{Pt}$ nanoparticles and higher electrochemical active surface area. 


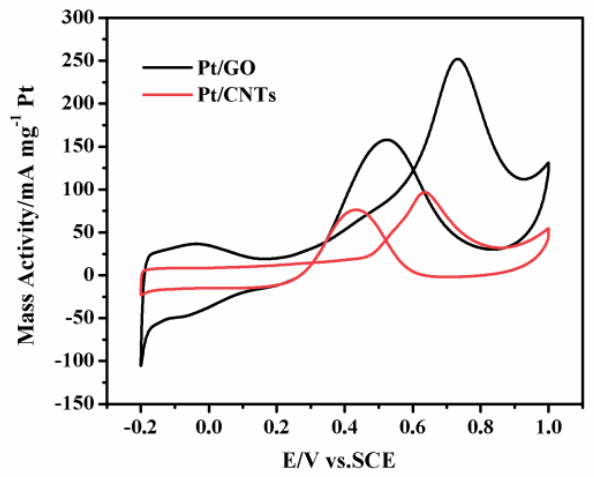

Figure 6. $\mathrm{N}_{2}$ saturated $0.5 \mathrm{M} \mathrm{H}_{2} \mathrm{SO}_{4}$ in $1.0 \mathrm{M} \mathrm{CH}_{3} \mathrm{OH}$ at a scan rate of $50 \mathrm{mV} / \mathrm{s}$ of the $\mathrm{Pt} / \mathrm{GO}$ and $\mathrm{Pt} / \mathrm{CNTs}$

As shown in Fig.7, the stabilities of methanol oxidation catalyzed by the two catalysts were also tested by chronoamperometry at constant potential. With the extension of polarization time, the activity of both catalysts decreases, which may be due to the loss or accumulation of catalysts with the extension of reaction time, and the formation of insoluble carbonates on the surface of catalysts by possible carbonaceous residues ${ }^{[19]}$. The initial current density of $\mathrm{Pt} / \mathrm{GO}$ is larger, and with the prolongation of polarization time, the decreasing trend of the curve is slow, and $\mathrm{Pt} / \mathrm{GO}$ shows a higher steady-state current density. The above structure shows that $\mathrm{Pt} / \mathrm{GO}$ has better catalytic stability for methanol oxidation. This is due to the better dispersion of Pt nanoparticles on GO carrier, which promotes the rapid transfer of reactants and products.

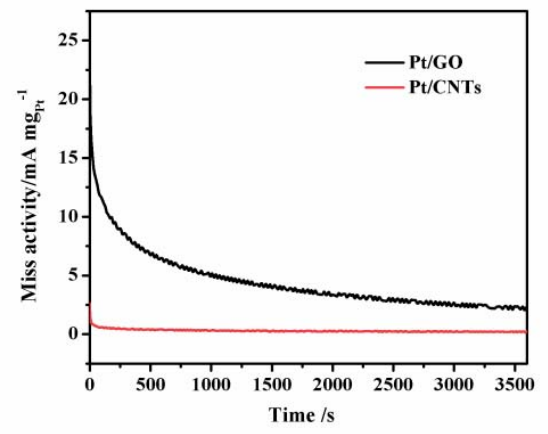

Figure 7. Chronoamperometric curves of $\mathrm{Pt} / \mathrm{GO}$ and $\mathrm{Pt} / \mathrm{CNTs}$ catalyst in at $0.6 \mathrm{~V}$ for $3600 \mathrm{~s}$ in the mix solution of $1 \mathrm{M}$

$\mathrm{CH}_{3} \mathrm{OH}+0.5 \mathrm{M} \mathrm{H}_{2} \mathrm{SO}_{4}$

\section{Conclusions}

In summary, the Pt nanoparticles supported on GO and CNTs were synthesized by wet chemical reduction method to catalyze methanol oxidation. The particle size of Pt supported on GO is much smaller than that on CNTs, which means that there are more active centres for methanol oxidation and the size effect of $\mathrm{Pt}$ is more significant.

\section{Acknowledgments}

The authors acknowledge Natural Science Foundation of Shanxi Province (201803D121122) and National Natural Science Foundation of China (51804191, 52071192).

\section{References}

1. K.M. Lin, F.C. Wang, Int. J. Hydrogen Energ., 46: 21083-21097 (2021)

2. D. Alqdeimat, P.G. Pickup, ECS Transactions, 97: 893-900 (2020)

3. C.F. Wang, Q.S. Li, C.M. Wang, Y.J. Zhang, W.L. Zhuge, Energy, 232: 121038 (2021)

4. Z.F. Wang, Y. Yang, Z.F. Zhao, et al., Nat. Commun., 12: 1982 (2021)

5. MTX Nguyen, MK Nguyen, PTT Pham, HKP Huynh, ST Nguyen, Electroanal. Chem., 888: 115180 (2021)

6. N. Mardini, Y. Bicer, Int. J. Hydrogen Energ., 46:13050-13060 (2021)

7. W. Yan., Y. Xiang, J. Zhang, S. Lu, S.P. Jiang, Adv. Sustain. Syst., 4 (2020)

8. G.X. Xu, Z.G. Wu, Z.Y. Xie, Z.L. Wei, J. Li, K.G. Qu, Y. Li, W.W. Cai, Int. J. Hydrogen Energ., 46: 9782-9789 (2020)

9. B.L. Garcia, VA Sethuraman, JW Weidner, R Dougal, RE White, J. Fuel Cell Sci. Tech., 1: 43 (2020)

10. D. Lee, Sujin Gok, Youngkwang Kim, Yung-Eun Sung, Eunjik Lee, Ji-Hoon Jang, Jee Youn Hwang, Oh Joong Kwon, Taeho Lim, Acs Appl. Mater. Inter., 12 (2020)

11. Y.X. Bao, B.W. Hao, J. Am. Chem. Soc., 134: 13934-13937 (2012)

12. H.C. Kim, R.K. Pramadewandaru, S. Lee, J.W. Hong, B. Korean Chem. Soc., 41:2 (2020)

13. Zeynep Daşdelen, Ali Özcan, Int. J. Hydrogen Energ., 45: 21881-21891 (2020)

14. W.L. Ding, X.L. Peng, Z.Z. Sun, K. Bi, Y. Zhang, Y.L. Wang, L. Ji, H.Y. He, Mater. Adv., 2: 2009-2020 (2021)

15. D. Tomida, A. Kumagai, K. Qiao, C. Yokoyama, Int. J. Thermophys, 27: 39 (2006)

16. X.L. Zhang, M.Y. Gang, J. Power Sources, 340: 22-31 (2017)

17. M. Xiao, J. Zhu, J.J. Ge, C. Liu, W. Xing, J. Power Sources, 281: 34-43 (2015)

18. X. Zhang, , J.X. Zhu, S.T. Chandra, Z.Y. Ma, H.J. Huang, J.F. Zhang, Z.Y. Lu, W. Huang, Y.P. Wu, ACS Appl. Mater. Interfaces, 17: 10858-10865 (2016)

19. M.L. Xiao, L.G. Feng, Nanoscale, 21: 9467-9471 (2015) 